\title{
El conocimiento de la adolescencia y su implicación en la práctica docente.
}

The knowledge of adolescence and its involvement in teaching practice.

DOI: 10.32870/sincronia.axxv.n79.35a21

Hugo Oswaldo Obledo Rodríguez

Escuela Normal Superior de Jalisco (MÉXICO)

CE: hugo.obledo@ensi.edu.mx

Esta obra está bajo una Licencia Creative Commons Atribución-NoComercial 4.0 Internacional

Recibido: 31/12/2019

Revisado: 02/10/2020

Aprobado: 10/11/2020

\section{RESUMEN}

Conocer al adolescente es necesario en toda práctica educativa. No podemos ver al alumno y al adolescente como si fueran dos cajas distintas a las que debemos llenar de conocimientos, como si fueran dos entidades aisladas una de otra. Al conocer la individualidad de los estudiantes, podremos identificar una serie de factores individuales, familiares, sociales, actitudinales etc., que nos darán muchas herramientas para mejorar nuestro trabajo en las aulas. Los cambios emocionales, psicológicos, la búsqueda de la identidad personal, la aceptación en un grupo, la separación de los padres, entre otras situaciones, son aspectos importantes para el desarrollo de la adolescencia. Es por eso que en este artículo se ofrece un análisis sobre la adolescencia, con el objetivo de conocer los cambios que los alumnos presentan en esta etapa, así como factores de orden individual, familiar y social que influirán en el alumno de forma notable; y finalmente, una serie de puntos a considerar en nuestro proceso de enseñanza como fruto de este análisis.

Palabras Clave: Adolescencia. Familia. Escuela. Práctica docente.

\section{ABSTRACT}

Knowing the adolescent is necessary in every teaching practice. We cannot see the student and the adolescent as if they were two different boxes in which we must fill them with knowledge, as if they 
were two entities isolated from each other. By knowing the students' individuality, we can identify a series of individual, family, social, attitudinal factors etc., which will give us many tools to improve our work in the classroom. Emotional and psychological changes, the search for personal identity, acceptance in a group, separation from parents, among other situations, are important aspects for the development of adolescence. That is why in this article it offers an analysis on adolescence, to know the changes that students present in this stage, as well as factors of individual, family and social order that will influence the student remarkably; and finally, a series of points to consider in our teaching process as the result of this analysis.

Keywords: Adolescent. Family. School. Teaching practice.

\section{La adolescencia}

Hablar sobre la adolescencia es sin duda alguna un tema que da para muchas cuestiones, que van más allá de los factores físicos y biológicos. Podemos decir en términos generales que es una etapa que comienza a partir de los 11-12 hasta los 15 años de edad. Para Lefrancois (2000)

[...] "la adolescencia es la transición entre la niñez y la edad adulta, el periodo durante el cual los niños han logrado la madurez sexual pero aún no han asumido las funciones y responsabilidades -o lo derechos- que acompañan la condición del adulto pleno." (Pág. 501).

A la par, Clauss, G y Hiebsch, H. (1996) nos dicen que: "A esta fase del desarrollo se le llama prepubupertad porque su final marca el inicio de la pubertad (maduración sexual). Esta fase es un periodo de labilización o inestabilidad". (Pág. 111) En ambas definiciones se hace notar que la adolescencia marca el final de la niñez.

La mayoría de los expertos concuerdan que la adolescencia es una etapa difícil, tanto para el niño, como para los padres, maestros o tutores; pues es un primer puente entre la infancia, la cual, hasta ese momento, había sido una etapa generalmente de juegos, diversión, cuidados, libre de compromisos y responsabilidades, hacía la etapa de la juventud, tiempo de mayor libertad y experimentación. 
En este periodo, los adolescentes comienzan a sentirse alejados de la niñez, y empiezan un largo camino para conformar una identidad personal. (Bandura, y Walters, 1974) En este proceso, tienden a imitar diferentes personalidades, tanto de amigos, como de adultos; es un momento de alejamiento y acercamiento con la figura de autoridad, a la cual rechazan, pero que al mismo tiempo necesitan; quieren un trato igual de sus superiores, y a la vez siguen con actitudes infantiles como las bromas, los juegos, la falta de seriedad y responsabilidades. El adolescente es un ir y venir en su proceso de cambio. Busca la independencia y libertad de decidir, y enfrentarse a lo nuevo por ellos mismos, pero sin las restricciones de los adultos, y al ver que no pueden o que eso conlleva ciertas responsabilidades que asumir, regresan a ese lugar de dependencia de los padres o la figura de autoridad. Eso explica que en ocasiones tengan actitudes eventualmente maduras y luego regresen a los comportamientos o comentarios infantiles. Este comportamiento se verá reflejado tanto en su casa como en la escuela, en aquel alumno que un día sorprende con comentarios tan prudentes y reflexivos, y luego con ocurrencias que lo regresan a su grado de inmadurez.

A la par que van creciendo, el alejamiento de los padres se da por esa misma necesidad de independencia. Buscan defender su conducta como un manifiesto de su independencia, así pues, desobedecer se vuelve parte de su idea de libertad. Son un tanto reacios a lo que los padres y maestros les dicen o presentan como "la verdad" de las cosas, por lo que tienden a buscar sus propias respuestas. De esta forma, suelen rechazar las charlas de moral de los padres y maestros sobre la importancia de comportarse de determinada forma, y sólo lo aplicarán si es que no las comprueban por sí mismos.

A menudo suelen sentirse incomprendidos por los demás, por lo que, si se sienten agredidos buscarán auto defenderse evitando decir lo que les pasa. Tienen confusión en su ser, sus constantes emociones son incomprensibles e innombrables para ellos. Pueden no sentirse valorados, odian las comparaciones, y tienden a preocuparse más por su aspecto físico.

Aunque exijan una independencia, necesitan una figura que les hable con claridad y les marque limites, y al mismo tiempo sentir que pueden tomar sus propias decisiones. Es una etapa 
en donde desarrollan muy poco el autoanálisis, les cuesta la reflexión de sus actos y las consecuencias a futuro y aunque lo hagan, no le toman mucha importancia. Piensan y viven el presente. Se interesan por su mundo interior, por lo que se piensa que pueden llegar a ser egoístas. Por supuesto esto también depende en gran forma del entorno, los valores que con el tiempo le han sido inculcados, sus actitudes y acciones no son actos que tengan una explicación.

No podemos considerar al adolescente como un fragmento aislado, separado de su propia historia, pues toda persona constituye un conjunto indisociable que pasa desde la infancia más temprana por una serie de transformaciones que marcan su individualidad. La forma en que cada niño aborde la adolescencia dependerá, en este sentido, de su proceso psicológico anterior. (Gispert, 1989, p. 48)

Al terminar la niñez se comienzan a romper los vínculos de seguridad que brindaba la familia. La inestabilidad emocional del adolescente es una de sus características que más manifiestan en esta etapa, cambian de un momento a otro, ya sea por motivos biológicos o circunstancias externas. Otro aspecto del adolescente es que aún no aprende a valorarse a sí mismo, depende emocionalmente de otros, de ahí que formar parte del grupo de amigos sea de gran importancia para ellos, a veces incluso, más que el estudio. Esa inestabilidad emocional puede afectar significativamente su comportamiento en el aula y afectar su rendimiento. Su actitud es itinerante, pendular entre la alegría y el optimismo de aprender y el desgano total e indiferencia ante las clases. Presta más atención a sus vivencias, se vuelve más introvertido y espiritual; al mismo tiempo le interesa mucho la convivencia con las demás personas. Es en su mayoría a partir de los 14-15 años, edad en la que generalmente entran a tercer grado de secundaria, cuando los juegos se vuelven más agresivos físicamente: empujones, corretearse y abrazarse, juegos corporales que se dan sobre todo en los hombres. Se intensifican sus emociones y las sensaciones del cuerpo, así como el deseo de abrazar y acariciar. En cuento a su lenguaje es más coloquial, orientado a las groserías, las bromas, y todos aquellos términos que se han vuelto "virales" en las redes sociales. Las cosas actuales es lo que más les impacta, pues forma parte de su presente. 
Otra de las características del adolescente es que llega a ser muy impulsivo, tanto en sus palabras como en sus acciones; esa impulsividad y el cúmulo de emociones le llevan a hacer prematuros juicios de valor, sin preguntarse los motivos o las causas, de ahí el inicio de tantos problemas que se dan por "chismes" o malos entendidos.

\section{Escuela}

En la adolescencia se inicia la educación secundaria. Es ahí cuando las exigencias escolares aumentan, los aprendizajes cambian, la currícula se vuelve más compleja y cargada en contenido, lo cual exige en el adolescente mayor esfuerzo, dedicación y control de sus tiempos y emociones. No obstante, de esta nueva exigencia, sigue teniendo muchos comportamientos de su etapa anterior, actitud que se convierte en un nuevo problema, sobre todo en primero de secundaria. Al iniciar esta etapa de cierta independencia de los padres, el adolescente buscará en el ámbito de la escuela nuevas amistades que puedan comprender su misma situación, buscará en el grupo el sentido de pertenencia, sentir que es querido y aceptado como es, aunque aún no defina su propia identidad. La familia deja ser el lugar primordial, ahora busca la pertenencia con los amigos, quienes le brindan la posibilidad de distintas experiencias, relaciones de confianza, aventuras, juegos, el amigo cómplice, y un poco después el descubrimiento de su sexualidad, el primer amor, etc. Esto puede llegar a generar grandes distracciones en su rendimiento. Gispert $(1989$, p.34) refiere sobre la amistad y la importancia de los amigos:

El grupo de amigos ofrece, por el contrario, la posibilidad de la vivencia compartida, del lazo mutuo de una particular identificación y la seguridad solidaria de los otros miembros. En el grupo pueden compartirse sin tapujos los estereotipos físicos y mentales que soportan los ideales de la pubertad: virilidad, estatura, fuerza y agresividad. La figura del líder surge como un compendio de características que los demás miembros del grupo desean también para sí: procurarán imitar sus actitudes y secundar sus acciones para ganar su aceptación. 
En ese anhelo de pertenencia y la búsqueda de una personalidad, el adolescente incursiona en una vestimenta, a veces extravagante o seria. Los peinados de moda, los juegos, los retos son parte de su experimentación. Le preocupa mucho lo que piensen sus compañeros y amigos, de ahí que entre ellos mismos usen el mismo lenguaje como un signo de pertenencia e identificación.

Dentro de su mismo grupo de amigos suelen ser muy hirientes con sus palabras, debido a que mucho de eso lo toman a broma, no miden sus comentarios ni las acciones que lastiman a otros, piensan que es una forma de querer encajar. Irónicamente, son al mismo tiempo frágiles a los comentarios de los demás. Al sentirse agredidos buscan refugio con una amiga o amigo que no los juzgue, en quien encontrarán un aliado en los trabajos escolares. De no ser así, optarán por distraerse en cualquier cosa individual o trabajar de forma aislada. Esto es un punto de observación para el docente, ya que los adolescentes son muy inteligentes, saben con quién trabajar, y con quién pueden jugar, por lo que aquel que es aceptado sólo por sus bromas, puede ser rechazado cuando es el tiempo de trabajar.

En esta misma etapa, el desarrollo de la personalidad y creatividad reluce, puede que aún su análisis no sea lo bastante desarrollado, pero lo compensan con la sencillez de sus respuestas, que suelen ser muy certeras. Sus habilidades y talentos las van desarrollando a medida que al ingresar a la escuela se ven en la necesidad de fomentar su creatividad, compromiso, esfuerzo, etc. Victoria Camps en su libro Creer en la educación: la asignatura pendiente (2008) nos habla que uno de los objetivos de la educación debe ser precisamente el desarrollo de la personalidad de los alumnosadolescentes, regresando a las bases fundamentales como el respeto, la convivencia y el esfuerzo. De ahí la importancia que la escuela fomente actitudes y valores dentro de su currícula, ya que la sociedad le mostrará al adolescente un mundo muchas veces alejado de los valores sociales y personales. El mismo Erikson (Lefrancois, 2000) nos habla sobre la importancia del entorno social de los niños, a lo que llamaba su desarrollo psicosocial, es decir, todos aquellos factores sociales que intervienen en el desarrollo de una personalidad. La idea central en la teoría de Erikson es el desarrollo de una identidad sana, lo que generará en el adolescente una confianza en sí mismo. Esta parte es importante en el espacio áulico, ya que el adolescente-alumno, buscará primeramente 
sentirse integrado, seguro de que pertenece al grupo, y así, al sentir confianza de su persona, su rendimiento académico será mejor, de lo contrario, buscará posiblemente primero sentirse parte del grupo antes que atender las labores escolares.

\section{Familia y escuela}

La educación en la etapa secundaria debe estar fuertemente apoyada por un modelo de familia que procure una comunicación con la escuela y el cuerpo docente, con el objetivo de comprender mejor los cambios que acontecen en el adolescente. Un modelo familiar que trasmita la importancia de la educación, y no solo como un fin de mero trámite, como algo que en la vida se tiene que hacer; si no por el contrario, ver la educación como un medio que, primeramente, le permitirá descubrir una serie de características, talentos, habilidades, etc., de sí mismo, al mismo tiempo que descubrirá lo que quisiera "ser" en un futuro ideal; y en segundo, el medio que le permitirá el "saber hacer" para lograr ese "ser".

El modelaje familiar es importante, ya que, en esta etapa, posiblemente el adolescente no se preocupe ni se pregunte por un futuro. Muchos de ellos únicamente viven un presente sin cuestionarse sobre las consecuencias ulteriores de sus actos o sus decisiones. De ahí la necesidad de la escuela como un espacio en el que adquiera conocimientos, descubra y desarrolle sus capacidades, aptitudes, verdaderos intereses, etc. Un estudio realizado en Navarra España sobre los adolescentes en la actualidad, nos habla precisamente que el adolescente- joven de hoy en día, sin bien no desestima el futuro, tiene un mayor interés por vivir el momento presente.

Una percepción ampliamente compartida por los entrevistados para este estudio consiste en que los jóvenes viven y piensan sólo en relación con su cotidianeidad. Más de dos terceras partes de entrevistados señalaron que los adolescentes actuales se preocupan más por el presente, no obstante, otros datos del propio estudio muestran que en sus preocupaciones actuales el futuro no pasa desapercibido. (Eresta, s/f) 
Es por eso que resulta tan complicado motivar a un adolescente en aprender determinados temas bajo el argumento de que en algún momento de su vida lo va a necesitar, pues desde su presente piensa que en realidad nadie podría asegurarlo, pues sus intereses son otros o que, en todo caso, siempre habrá tiempo para aprenderlo. De ahí la importancia que el docente busque estrategias distintas para la motivación. Es necesario también tomar en cuenta siempre el trasfondo de ese pensamiento porque, si bien, es natural a su edad, también puede ser influenciado desde su entorno. Por este y otros motivos, la educación en la escuela debe aspirar a inculcar conocimientos académicos, personales, hábitos de estudio; tomar en cuenta el contexto individual y familiar de los estudiantes, incluso averiguar, aunque esto entra más en la labor docente, cuál es la visión que los padres tienen sobre la educación, ya que puede estar en disonancia con la del maestro y la escuela, así como la visión que el adolescente va formando de sí mismo con relación a la escuela como un medio para su realización personal y profesional. Es posible que un estudiante que vea en su seno familiar una nula exigencia sobre su rendimiento académico, encuentre la forma sencilla de sobrellevar las cosas. Como muchos, buscará solamente aprobar las materias, sin que exista en él mismo un interés mayor por superarse o aprender más. En todo caso, será poca la preocupación, o tendrá una exigencia a corto plazo basándose en el mínimo esfuerzo.

En su artículo "Contextos multiculturales, enfoques de aprendizaje y rendimiento académico en el alumnado de educación secundaria" (Barca, 2008), nos habla el autor sobre tres tipos de enfoques que tanto los estudiantes de secundaria y de universidad adoptan en sus procesos de estudio. El primero de ellos es el Enfoque superficial, en el que los estudiantes se inclinan más por un aprendizaje memorístico, sin esforzarse tanto en las actividades; su objetivo es básicamente el obtener las calificaciones mínimas aprobatorias, sin interesarles si las actividades que realizan les ayudan a su aprendizaje. El segundo es el Enfoque profundo, aquí los alumnos organizan la información, para posteriormente reelaborarla, esto les permite tener una mejor comprensión, pues se sienten responsables de la adquisición de su propio aprendizaje por lo que se involucran más. Y finalmente es el Enfoque de logro, en este enfoque los estudiantes ven el aprendizaje como 
una herramienta de competición que les permite aumentar su autoestima al obtener mejores calificaciones que el resto de sus compañeros.

Su mentalidad es práctica, de ahí tantos cuestionamientos que hacen a los maestros sobre la utilidad de las asignaturas, utilidad que no siempre ven reflejada en su vida diaria. El adolescente de hoy, contrario al de antes, ya no busca la retención de información, ya que todo lo tiene a su alcance. Para algunos, su pensamiento ante el estudio es de no necesitarlo. Por eso resulta difícil el plantearles situaciones ulteriores como "estudia y escribe tal información porque algún día lo vas a utilizar". Pero el adolescente actual piensa que en su vida diaria esa información o trabajo no le es en realidad tan esencial, y en todo caso, cuando lo necesite la podrá buscar, pues todo está a su alcance a través de su celular o de la computadora o cualquier otro dispositivo que le permita investigar. Su pregunta es ¿para qué?, y no el ¿por qué? Las respuestas a estas preguntas tendrán estrecha relación con su interés para realizarlas.

\section{Familia y sociedad}

Hablábamos de la importancia que el modelo familiar tiene para el rendimiento escolar y personal del adolescente y la relación que Erikson nos ofrece entre los factores sociales y culturales y el desarrollo de la personalidad. Uno de los grandes problemas que tenemos como sociedad es la falta de consecuencias, o, dicho de otra forma, la impunidad. Quizá pareciera que esto es algo que concierne estrictamente a la clase política, o a los empresarios, o a los encargados de legislar y hacer justicia; pero es algo que afecta desde los círculos de poder hasta la juventud, adolescencia y la niñez. El hecho de que alguien haga algo malo y no pase nada, o como decimos de forma coloquial, "nos salimos con la nuestra" al momento de hacer algo indebido, pero "correcto" para nosotros, a veces en forma de venganza, o para evitar un perjuicio, una tarea, o algo que debíamos hacer, es un problema que sin darnos cuenta nos genera una serie de situaciones negativas que tarde o temprano nos afectan a todos. Como sociedad, nos cuesta trabajo asumir y hacer lo que nos corresponde: llevar a cabo mi responsabilidad. 
En muchas ocasiones, el adolescente tiende a culpar a otros de sus propias responsabilidades, con frases como: no entregué el trabajo a tiempo porque mi impresora no tiene tinta; no hice la tarea porque un día anterior no vine y no supe qué dejaron; llegué tarde porque mi papá no me levantó temprano o no sonó el despertador; no traigo mi uniforme completo porque mi mamá no alcanzó a lavar; yo me porto bien, mis amigos me distraen; y un sinfín de disculpas y justificaciones que presentan para evitar asumir su responsabilidad. El problema es que, no parecemos vislumbrar las graves consecuencias que nos trae como sociedad cuando empezamos a disculparnos por no hacer nuestras obligaciones. El adolescente entonces va creando una serie de disculpas para cada actividad no hecha, y como decíamos, es un problema que se da en todos los ámbitos, por lo que es realmente una responsabilidad social, escolar y familiar, no sólo individual. El hecho de querer justificar todo y peor aún aceptarlo y verlo como normal, estamos coadyuvando a generar mayores problemas.

Cuando normalizamos estos comportamientos o les vamos quitando la verdadera dimensión de nuestros actos, le estamos demostrando a un niño que no es importante ser sincero, responsable, honesto, ni trabajador. Con esto provocamos impunidad en los actos, es decir, que lo malo que yo hice no tenga consecuencias; de ahí que escuchemos también frases como: es normal llegar tarde; es normal hacer lo que quiera si eso me hace feliz; es normal hacer trampa en los exámenes mientras no me descubran; es normal hacerme el gracioso humillando a los demás si con eso me aceptan etc. Al normalizar estas conductas, en lugar de formar adolescentes-alumnos que sean responsables, conscientes de sus actos y consecuencias, les estamos diciendo que no importan los valores, ni esforzarse por cumplir sus deberes; lo importante es socializar y tener amigos que piensen igual que él para que le brinden oportunidades. El adolescente, entonces, tenderá culpar a los otros de su responsabilidad: es otro el que comenzó, yo lo golpeé porque me dijo algo que no me agradó; no hice la tarea porque nadie me dijo que dejaron; no la entregué porque el maestro no me la pidió; y tanto en casa como en la escuela y en la sociedad en general se realizarán las mismas problemáticas. 
Si los niños-adolescentes son educados con solo tener derechos, pero sin ningún deber ni responsabilidad que asumir, tarde que temprano terminarán afectándose a sí mismos y afectando a los demás, sin saber de qué forma poder corregirlos, llegando al grado que todos conocemos de un maestro que no sabe qué más hacer para que el alumno trabaje, y un padre de familia que siente que su hijo se le ha salido de las manos. Es decir, un niño que no aceptará ningún regaño y cuando se le intente sancionar responderá de forma agresiva. Por eso, es importante que el adolescente en esa libertad que tanto anhela, entienda que también debe sufrir las consecuencias de sus actos. Solaparle sus obligaciones, sólo provocará que justifique y culpe por lo que debió hacer y por ende, estaremos fallando como padres, maestros y sociedad. Es necesario que reconozca sus errores, que reflexionen en lo que hizo mal. Si no, lo único que hará es buscar privilegios, comodidades, y al enfrentarse a la verdadera responsabilidad no querrá hacerlo y vendrán los conflictos que afectarán a su persona y su rendimiento escolar.

En su obra Psicología del niño escolar (1996) dentro de la Colección pedagógica, G. Clauss, H., y Hiebsch, $\mathrm{H}$ nos dicen:

Con singular facilidad se producen conflictos en el seno de la familia por no cumplir el pre pubescente con prontitud y sin "chistar" los encargos y las órdenes de sus padres. En el curso de la pre pubertad se producen actos de desobediencia y resistencia con más frecuencia que en las otras etapas del desarrollo, incluso en familias que se distinguen por su clima social favorable y su buena formación educativa. (p. 152)

Para un docente, le resultarán familiar esas mismas actitudes reflejadas en el aula: la desobediencia, los gestos ante alguna indicación que no quieren seguir o las respuestas en ocasiones groseras, son vistas tanto en la casa, como en la escuela. Es por eso que no debemos entender al estudiante y adolescente como entidades separadas, ya que una depende y afecta a la otra.

En esta etapa de su desarrollo, el adolescente comienza a tener sentimientos de autosuficiencia, por lo que buscará en varias ocasiones medir a las autoridades. Ese mismo acto lo hace tanto con sus padres, con quienes por ejemplo, buscará con insistencia algún permiso, o la 
dispensa de un castigo, midiendo hasta qué punto los padres se mantienen en su postura o cambian su decisión, y lo mismo sucederá con el maestro, cuando escuchamos de los alumnos decir con cuál maestro deben trabajar y con quién no. Al mismo tiempo que miden y se sienten capaces, encuentran en el ámbito escolar el reforzamiento de los amigos, por lo que se comienzan a vislumbrar los juegos agresivos, las bromas y groserías. El alumno se siente protegido con sus compañeros, quienes se retan para hacer travesuras. Dentro de la misma obra encontramos:

No es difícil penetrar en las razones psicológicas de esta actitud rebelde del prepuber inclinado a frecuentes groserías. Estriban, en resumidas cuentas, en la contradicción esencial que caracteriza la primera fase pubecente: por una parte, el adolescente tiene la vivencia de que él ya sabe y puede muchas cosas y, por otra parte, se da cuenta de que aún le falta mucho especialmente en madurez y dominio de las situaciones. La conciencia que de manera rápida se ha desarrollado en él de su propia capacidad le da arrestos para conducirse con seguridad, hasta con arrogancia a veces, conducta que con demasiada frecuencia va seguida de fracasos y contra golpes que lo desilusionan. Así vemos al prepuber arrastrado de un lado a otro entre una consciencia exagerada de su propio valor y el sentimiento de su insuficiencia. Esto, precisamente, es lo que muchos mocitos no quieren confesar y tratan de compensar con una conducta rebelde, ruidosa, más aún, escandalosa, frente a las demás personas, especialmente si son autoridades. (p. 159)

El adolescente, de la misma manera que mide hasta qué punto puede llegar con sus actitudes y conducta, lo mismo puede hacer con su rendimiento académico. Es decir, es capaz de identificar, con cierta complacencia de padres y maestros, lo mínimo necesario para pasar sin que tengan consecuencias. Puede mediar entre lo que esperan de él, ya sea familiares o maestro, y lo que él mismo quiere; analiza y comprende si puede solucionar el problema con el mínimo esfuerzo, plantea pros y contras y saca ventaja de ello.

Es por eso tan importante inculcarles desde temprana edad los valores del compromiso, del respeto, el control de sus emociones y aceptación de consecuencias. Ya que con esto le ayudamos en esta etapa de enfrentamiento de la autoridad, debido, como decíamos, a los primeros 
sentimientos de independencia que sienten, por lo que se vuelven menos abiertos a los consejos o regaños.

Por estos motivos, es trascendental que el adolescente cuente con reglas establecidas y operantes, para que encuentre en su casa y en la escuela lugares de seguridad y pueda aprender a auto determinarse y sepa enfrentar y resolver los constantes cambios que son intrínsecos de su etapa. Tener un contexto que dé seguridad y que maneje adecuadamente las crisis que con frecuencia se presentan en esta etapa de la vida. Ruth Guillén de Maldonado (2005) nos dice que los adolescentes son el resultado de una serie de condiciones que se dan dentro de la familia y su contexto. A esto le sumamos por supuesto los factores ideológicos que condicionan ciertos comportamientos y actitudes, como los compañeros de escuela, maestros, medios de comunicación etc. Lo que se debe desarrollar en los niños junto con sus aprendizajes y competencias, son valores como el compromiso, resiliencia, responsabilidad, tanto en casa como en la escuela. Hacerles saber que tienen la libertad de sus acciones, pero también hacerlo conscientes sobre los alcances de sus actos; una libertad con sus debidos y necesarios limites que marquen su vida. Álava Reyes nos dice al respecto:

A ver, todos los niños necesitan pautas, normas, límites, es un error no ponérselos, como es un error pensar que bueno, que esto no es para tanto, y ceder para evitar males mayores. La mayoría de los niños de hoy les educan en el consumismo, y si les damos todo a cambio de nada, empiezan por no dar valor a las cosas y terminan por no dar valor a las personas. Un niño, una niña, se tiene que frustrar para poder aprender, para elaborar recursos. Esto es uno de los grandes dramas que tenemos ahora mismo. Es decir, la frustración, en realidad, es el camino del conocimiento, y esa es la llave de la inteligencia. (Álvar, s/f).

El adolescente hoy en día pasa mucho tiempo a solas. El aumento de las escuelas de tiempo completo, aunado a la necesidad actual de que padre y madre trabajen, provoca que el niñoadolescente crezca sin los suficientes hábitos de estudio y disciplina. Sin una figura de autoridad que le esté marcando las obligaciones, padre-maestro, regresará a esa parte infantil de los juegos, la 
diversión, sin hacer caso a los compromisos que por su nueva etapa ha adquirido. De esta forma, lo que buscará será entretenerse con cualquier cosa, video juegos, celular, redes sociales, calle, actividades que no le generen provecho alguno, pues su interés será solamente entretenerse, producto de su mismo aburrimiento y libertad en demasía, pero no desarrollará ni descubrirá nuevas habilidades, capacidades personales y sociales, menos aún, lo que se espera de él en el ámbito académico.

\section{Diagnóstico.}

Dentro del colegio José Cardenal Salazar se elaboró un cuestionario de 15 preguntas, las cuales versan sobre los gustos personales de los alumnos, cómo creen que son en cuanto a su personalidad y preguntas relacionadas con su visión de la escuela, lo que les gusta, o les gustaría hacer en un futuro y la relación que esa meta tiene con la escuela, así como preguntas que invitaban a un autoanálisis de su rendimiento.

Para la construcción de este cuestionario se entrevistó a algunos alumnos de manera informal, más tratado como una charla. Con base en esa plática se generaron las preguntas. Fue bastante enriquecedor el elaborarlo de esta forma porque apreciamos respuestas ya presupuestadas por las pláticas anteriores, y descubrimos otras que no esperábamos. De forma general, dejamos una breve información sobre las respuestas que más nos parecieron significativas, ya que tenían relación con su personalidad y la escuela. Dejaremos la sola inicial del alumno o alumna por motivos de respeto, y además, usaremos los términos de buen, medio y bajo rendimiento por su nivel de calificaciones y de cumplimiento.

\section{Grado. 13 alumnos}

G. Alumna con buen rendimiento académico, se conforma con pasar, pero trata de tener buen promedio por la presión de su mamá. En ella, nos sorprendió su respuesta. 
R. Alumno con bajo nivel académico. Presenta muy baja autoestima. Sus respuestas son cortas y no son claras, reflejan sus problemas personales y poca seriedad al responder. En este caso, las respuestas comprobaron las pláticas anteriores

P. Alumna con buena capacidad. Para ella su comportamiento depende del lugar. Es reflexiva en su conducta y las consecuencias de sus actos, pero no comprende aún a qué se deba su actitud y los cambios que está pasando.

E. Alumna cumplida. Tiene un apoyo de sus padres sobre el esfuerzo presente con relación a su futuro.

A. Alumna de rendimiento medio. Siente que la escuela no le ha ayudado a expresarse, este elemento lo repite mucho en sus respuestas. Tiene ideas de lo que quiere hacer en un futuro y sabe que la escuela le ayudará.

J. Alumno de buen rendimiento. Tiene un objetivo definido, y lo trabaja desde hoy. Buena relación con su familia, valora el esfuerzo de sus papás tratando de obtener buenas calificaciones

E. Alumna de buena capacidad, pero con problemas actitudinales. Presenta mucha confusión de cómo es. Poca comunicación en casa, pues cree que no tiene apoyo. Culpa su rendimiento a las amistades.

J. Apoyo en casa, consciente de sus habilidades, relaciona el esfuerzo presente con el bien futuro, valora el esfuerzo de sus papás esforzándose

P. Alumna promedio, llegando al bajo rendimiento. Poca comunicación con su familia, reflexiva en sus actos, admite que le gana el "relajo", no comprende el cambio de primaria a secundaria en su bajo rendimiento.

C. Alumno promedio, despreocupado, esfuerzo mínimo en los trabajos, y si lo hace es para evitar regaños, poco autoanálisis.

P. Alumna cumplida, relaciona el esfuerzo con la preparación futura.

A. Alumno cumplido. Buena relación con padres, pero poca reflexión en la importancia de las actividades escolares, el esfuerzo se da por presión de su mamá o evitar un castigo 
M. Bajo rendimiento académico, presenta problemas emocionales y de autoestima, culpa de esto a sus papás, quienes la desvalorizan mucho. Sus respuestas no son claras. En este caso, comprobamos las respuestas con la plática previa.

\section{2do grado. 8 alumnos}

L. Alumno de bajo rendimiento. Sus respuestas son hechas a broma, a juego, nula reflexión de sí mismo y de la escuela. Mala relación con su papá, a quien ha ofendido en varias ocasiones. Tiene problemas de valorización. Considera que no es bueno para nada, pues así se lo han hecho saber. Sin embargo, es un alumno muy respetuoso y obediente.

D. Alumna promedio. Buen apoyo de su familia, relaciona la escuela con un futuro mejor, le cuesta un poco los trabajos. Presenta un déficit de atención.

E. Alumno de bajo rendimiento. Mucho interés en los video juegos y el futbol. Apoyo de sus padres casi al grado de solaparle. Mínimo esfuerzo en sus actividades, poca reflexión de sus actos y consecuencias.

D. Alumno de bajo rendimiento. Buena comunicación con sus padres. Presenta el mínimo esfuerzo en sus trabajos. Prefiere no seguir estudiando porque piensa que en la escuela no hace lo que le gusta, pero piensa que lo necesitará en su futuro. El esfuerzo que hace es por sus papás, quienes le apoyan que con que pase está bien, por lo que sólo se preocupa por pasar.

U. Alumno de buen rendimiento. Buena relación con su mamá, relaciona su interés futuro con la escuela, comprende lo que se le dificulta y se esfuerza.

D. Alumno de buen rendimiento. Buena relación con padres, reflexiona sus actos, su esfuerzo se debe también a la influencia moral de sus papás, pues los ve como ejemplo. Se siente bien consigo mismo y su desempeño.

K. Alumno promedio. Apoyo de sus padres, se esfuerza en cumplir, pero no se obsesiona. Poco análisis de su futuro, su esfuerzo es solo porque sabe que es necesario, pero no lo relaciona aún con algo futuro, aun así, es crítico con sus actos presentes. 
C. Alumno de buena capacidad, pero con bajo rendimiento. Buena relación con sus padres. Su bajo rendimiento se debía a la falta de consecuencias en casa. Despreocupado. Tiene idea de lo que quiere ser y lo relaciona con su presente. En él se dio un cambio en el tercer trimestre, confiesa que apenas se dio cuenta de la importancia de esforzarse desde ahora. En una entrevista persona mencionó que su esfuerzo se debe también a seguir con sus amigos en el siguiente grado, aunque sabe que si no lo logra fue por su flojera.

\section{3er grado. 16 alumnos}

N. Alumno de bajo rendimiento académico, aunque bueno en matemáticas. Comenta que trabaja cuando es importante, no le gusta el estudio. Poca comunicación con sus papás sobre la escuela, pero considera que sí lo apoyan; siente que él mismo no da lo mejor que tiene: en sus respuestas enfatiza mucho que es un flojo, "huevon", por lo que piensa que con que pase está bien. Considera que sólo debería calificarse con un examen porque con eso se demuestra que el alumno sabe, considera que lo demás no es importante y también le da "flojera".

P. Alumna promedio a buen rendimiento. Buena relación con sus padres, quienes la motivan para esforzase y no ser del "montón". Tiene una idea a futuro y encuentra la importancia de esforzarse por conseguirlo; presenta buen análisis de sus actos y consecuencias. Considera que dio un bajón en la secundaria porque sus papás le dijeron que ya era momento de que ella misma "se las arreglara" S. Alumna de buen rendimiento. Buena relación, convivencia y apoyo de sus padres. Considera que la escuela le ayuda para conocerse más y saber qué le gustaría ser. Piensa que el esfuerzo que hace en la escuela le va ayudar en un futuro para lo que quiera dedicarse

P. Alumno promedio a buen rendimiento. Apoyo de sus padres. Considera que esforzarse en la escuela le ayudará en un futuro, aunque también su esfuerzo lo hace para evitar algún regaño de sus padres.

P. Alumno de bajo rendimiento. Respuestas generales, poco críticas hacia su persona y la escuela. Presenta el mínimo esfuerzo, aunque sabe que puede dar más. Se ve a sí mismo como 
irresponsable. En una entrevista comentó que el bajo rendimiento que presentaba se debió al darse cuenta que no pasaba nada si reprobaba.

E. Alumno de buen rendimiento. Buena relación con sus papás, comprende que la escuela le ayudará a tener una carrea y hacer lo que le gusta.

N. Alumno promedio, respuestas cortas. Buena relación con sus papás, aunque no se comunica del todo. Entiende que la escuela le ayudará a ser un profesionista, sin embargo, considera que la flojera le gana, por lo que le cuesta trabajo estudiar y hacer tarea.

P. Alumna promedio. Apoyo de sus padres, sabe que la escuela le ayudará en lo que quiere hacer en un futuro. Tiene buena percepción de sí misma, aunque le cuesta trabajo algunas cosas se esfuerza. D. Alumna promedio. Poca relación con su mamá, pues siente que la ha rechazado. Tiene una idea de su futuro y sabe que la escuela importante. Afirma que los problemas en su familia le han afectado.

D. Alumno promedio a buen rendimiento. Mucho apoyo de sus padres en cuestiones académicas, se ve con un futuro y sabe que la escuela le ayudará a eso, además de que sus padres lo alientan mucho.

A. Alumno promedio. Mucho apoyo de sus padres, reflexiona su presente con el futuro y se esfuerza. También piensa que con que pase está bien, pero si tiene mejores notas no estaría mal.

G. Alumno de buen rendimiento. Se esfuerza en cumplir. Platica con sus papás quienes le aconsejan y brindan alternativas. Aún no decide lo que quiere ser, pero se ve como alguien serio y trabajador y la escuela le ayudará a tener un buen futuro. Algunos problemas en la familia le afectan emocionalmente y hacen que baje su rendimiento

A. Alumna promedio hacia abajo. Tiene el apoyo de sus padres. Se ve como empresaria y sabe que debe esforzarse desde ahora, aunque acepta que en ocasiones le gana la flojera. Presenta también cierta confusión con sus actos.

M. Alumna de bajo rendimiento. No comentó sobre la relación con sus padres. En este caso sólo tiene papá. Es reflexiva de sí misma, se sabe con muchos cambios emocionales, reflexiona lo que hace y lo que le afectará. Considera que tiene baja capacidad de pensamiento, y cree que ella no es 
lo que esperan los "profes", y eso le pone mal. Afirma que le han faltado ganas y que debe cambiar. En ella las respuestas fueron las esperadas, sus problemas emocionales y familiares han sido un detonante negativo.

D. Alumno bajo rendimiento. Platica muy poco con su familia, de hecho, pasa mucho tiempo solo. Aún no tiene una idea de lo que quisiera ser, pero tampoco tiene ganas de preguntarse o hacer algo. Considera que cuando se esfuerza no es suficiente. Quiere seguir estudiando y piensa que debe dejar la flojera y el desinterés.

M. Alumna de buen rendimiento. Mucho apoyo de sus padres y buena relación. Les comenta todo y ellos le apoyan y aconsejan con argumentos, eso le agrada. Tiene una idea de vida a futuro. Analiza sus actos y comprende la importancia de esforzarse en este momento para logra su objetivo.

\section{Resultados}

Hemos sustraído algunas conclusiones de las respuestas de los tres grados, considerando que los alumnos con buen rendimiento se deben a los siguientes factores:

- Valoran el esfuerzo de sus padres

- Relacionan la escuela con lo que les gustaría ser de grandes.

- Comprenden que, aunque aún no tengan una idea de lo que les gustaría ser, la escuela les ayudará para prepararse.

- Están presionados por sus padres para obtener buenas notas, o se esfuerzan para evitar un castigo.

- Tienen buena relación afectiva con sus papás, tienen comunicación y confianza.

- Tienen admiración y apoyo moral de los papás. Los ven como un ejemplo a seguir, les creen y confían en lo que les dicen y exigen, porque consideran que son coherentes entre lo que les piden y lo que ellos son y hacen.

- La motivación de los amigos. 
Entre los aspectos que determinaban un bajo rendimiento encontramos los siguientes:

- Problemas relacionados con su familia, alguna pérdida, separación, etc.

- Conflictos emocionales, confusión de roles, cambios en su persona, sin saber a qué se debe. Este punto sobre todo en los de primer grado.

- Poca auto crítica de sus actos, culpar a otros de sus malos resultados.

- Falta de autocontrol.

- Falta de consecuencias de sus padres. De ahí el desinterés, la flojera o despreocupación de cumplir, o de hacer el mínimo esfuerzo. Este fue uno de los más reiterados.

- Poca exigencia de los padres "con que pases está bien"

- Baja autoestima, desvaloración de sí mismos, ya sea desde su casa o sus amigos, "si así creen que soy, así seré", lo que desencadena pensamientos como "no sirvo de nada" "no tengo habilidades o no sé nada", y por ende no les encuentran sentido a las cosas y no cumplen con los trabajos.

- En la escuela no pueden expresarse libremente en cuanto a su personalidad, intereses etc.

\section{Quehacer docente.}

La pregunta entonces es, ante este panorama, ¿qué puede hacer un maestro? Sin duda alguna, muchas cosas. Presentamos ahora algunos puntos a tener en cuenta.

\section{- Conocer la adolescencia}

Sobre todo, y reiterando la idea dicha anteriormente, ver al estudiante como un adolescente más, entender que no son dos personalidades distintas. Comprender lo esencial de esta etapa, pero sobre todo, comprender con quién estamos trabajando y que las necesidades no son las mismas. El interés del maestro puede ser la de enseñar los contenidos, cubrir el programa, terminar el libro, generar competencias, habilidades, mostrar evidencias de avances, en fin, dar resultados de su trabajo docente. Mientras que el estudiante, por su parte, lo que más le interesa es entenderse a sí mismo, comprender sus cambios, socializar, conocer y jugar con sus amigos, al mismo tiempo que cumple en mayor o menor esfuerzo con sus tareas escolares y obligaciones en casa. 


\section{- Conocer al alumno:}

Esta es, quizá, una de las primeras acciones que el docente debe darse el tiempo de hacer: conocer a sus alumnos, escucharlos. Una de las enmiendas indispensables para trabajar en el aula es que el docente pueda conocer a sus estudiantes, incluso darse a la tarea de saber cuál es la apreciación que el alumno tiene de sí mismo. El docente debe estar atento a escucharlo, incluso aquello de lo que no se dice, pero que puede advertir con los comportamientos. Lamentablemente muchas veces escuchamos para responder, no para comprender.

Cuando creemos que sabemos todo sobre el adolescente, y cuando dejamos de escuchar, se pierde la maravillosa oportunidad de entender por qué aquel estudiante no responde, no participa, no se involucra en las actividades o no tiene interés en la clase. Debemos entonces preguntarnos y ocuparnos en entenderlo desde su individualidad. Porque si bien esta etapa tiene particularidades, no todos los niños responden igual. Por este mismo motivo vemos que en la psicología humanista se interesan por la particularidad del niño:

La creencia humanista básica dice que es imposible describir el entorno, mucho menos a un niño, de manera realmente significativa, porque lo que constituye las características realmente importantes del entorno varía según los individuos: opinión llamada: fenomenología. Lo que la fenomenología subraya es la importancia de la visión que cada persona tiene del mundo y de sí misma. Para comprender la conducta de los niños, dice esta opinión, debemos tratar de percibir el mundo como ellos lo ven: desde la perspectiva de su conocimiento, sus experiencias, sus metas y aspiraciones. (Lefrancois, 2000, p. 91).

La tarea del maestro es identificar esas aspiraciones que el alumno tiene a corto y largo plazo; conocer también los ideales educativos que tienen sus papás, ya que pueden estar en disonancia con la del maestro, de ahí la importancia de hacer un diagnóstico de conocimientos previos, y también de aquellos que aporten en el conocimiento del alumno. Si un adolescente-alumno crece con la idea de que no es tan importante estudiar, o si no se le inculca pensamientos de superación y piensa que sólo basta con pasar, el alumno podrá entra en una zona de confort, la cual, no cambiará 
hasta que surja en él otro interés, posiblemente mucho después de la etapa secundaria, cuando las conocimientos y destrezas no se lograron desarrollar de la mejor forma, pudiendo provocar mayores problemas en las siguientes etapas. Debido a eso, el maestro tiene otra tarea: convencer al estudiante del bien que le hará aprovechar sus estudios y no sólo por el simple hecho de cumplir. De otra manera, caeríamos en una educación de imposición. Si realmente buscamos ayudar al alumno, no basta con que aprenda conocimientos, mucho menos si no forman parte de su vida presente, que es como decíamos, el tiempo inmediato que viven y les preocupa en mayor medida.

Si el alumno descubre la importancia de ese "bien" que busca tanto el maestro como la familia, ya no verá la escuela como una imposición, o al menos tendrá un mejor ánimo, una actitud distinta ante las actividades. Por eso, el docente debe buscar desarrollar en los adolescentes la satisfacción de hacer "bien" las actividades. Otro aspecto que se relaciona con la labor del maestro y el conocimiento del alumno es la motivación. Aristóteles decía que para entender algunos fenómenos era necesario saber el motivo por el que ocurrían. Es por eso que el maestro no debe quedarse con explicaciones simplistas como que el alumno es flojo, no le interesa tal actividad o materia, aunque pueda ser en parte cierto, pero no es necesariamente un factor determinante. El maestro debe conocer al alumno para motivarlo, descubrir aquellos fenómenos que lo hacen decidirse actuar en una acción específica. "[...] en la vida cotidiana la conducta siempre está regida por la intención de hacer una cosa u otra. Dicho de otro modo, toda conducta es motivada". (Bolles, 1990, p. 82) No basta con una reprensión o indicación momentánea, es preciso que el docente poco a poco descubra las motivaciones del alumno para dirigir su conducta a través de la motivación.

\section{- Generar en el alumno una reflexión crítica de sí mismo y de sus actos}

Los contenidos de un tema pueden trabajarse de tal forma, que el alumno reflexione sobre las consecuencias de sus actos, incluso apoyarse con experiencias de la vida diaria, como por ejemplo de algún personaje del presente inmediato, vivencias personales o algún personaje famoso, con el fin de que el alumno desarrolle el sentido de la responsabilidad y buena actitud para afrontar los problemas personales, grupales, sociales etc., ya que al afrontar los conflictos también desarrollará en su persona valores, actitudes positivas, reacciones adecuadas y control de sus emociones. Al ver 
un análisis de sí mismo, podrá descubrir aquellos conflictos que son ocasionados por su actitud y podrá poco a poco resolverlos; de otra forma, seguirá con esa actitud de culpabilizar a los demás de sus consecuencias.

\section{- Disciplina}

Este punto va ligado con el anterior, pues al analizarse a sí mismo, su conducta también se verá modificada. Una de las acciones que comúnmente acontece a los maestros con los alumnos, sobre todo en edad adolescente, es que actúan y reaccionan de forma inesperada. Muchas veces no sabemos por qué un alumno hace determinada acción, o por qué dijo tal o cual palabra o contestación; el maestro en esos casos puede reaccionar de forma emocional, sin ser esa reacción la más adecuada. Es importante reconocer que en esta etapa pueden presentarse cambios de emociones, por lo que en un momento podrán ser rebeldes en hacer las tareas y luego ser los más cumplidos; un día ser los más inquietos y otro día los más tranquilos.

Es importante que el maestro antes de reaccionar de forma emocional averigüe no solo lo que ocurre, si no también lo que está pasando por la mente del alumno al realizar determinada acción; esto tiene al menos dos vertientes: la primera es que el niño no apague aquella emoción o aquello que lo motivó, y que quizá puede ser por algo del mismo tema; y la segunda y más importante, que el alumno reconozca y analice por qué actúa de esa forma; es decir, que identifique las causas y efectos de sus actos. Con esto generamos y ayudamos a que desarrollen su autodeterminación, logrando reconocer el lugar, sus emociones, pensamientos etc., es decir, por qué hace lo que hace. De otra forma, generamos niños que sólo actúan por sus emociones sin ser conscientes de lo que hacen y el daño que generan. Daniel J. Siegel (2018) afirma que la disciplina no debe verse como un castigo, si no como una enseñanza, la disciplina puede evitar un comportamiento, pero no enseña nada y lo que se conseguirá es que el niño sólo busque salirse con la suya.

El docente debe saber enfrentarse con tranquilidad a los constantes retos del alumno, pues es una edad en la que dudan y cuestionan todo lo que se les dice como verdad. El incluir en las planeaciones momentos para la realización de dinámicas de integración o del manejo de las 
emociones son también herramientas para que mejore su conducta, reflexione y se genere un mejor ambiente en el salón de clases, y por ende, mejorar la educación. Las dinámicas sirven también como un cambio a lo monótono, un descanso mental y físico que pueden llegar a ser las clases en determinados tiempos del día, o del calendario escolar.

Ocurre también que el adolescente en ocasiones intenta hacer creer que está cumpliendo una indicación que se le dio, pero en realidad lo que está haciendo es hacer creer que lo está haciendo: hace como que limpia su cuarto, y hace que como copia lo escrito en el pintarrón o cualquier otra actividad que se le dejó hacer. Es necesario que el docente no forme parte de ese juego. Debe hacerle saber al alumno que le ha descubierto esa actitud, de lo contrario estará siendo cómplice de esa falta de responsabilidad, o peor aún, si lo advierte y no hace algo, carecerá de moral alguna frente al alumno, pues él podrá fácilmente argumentar, con tal de librarse de su culpabilidad que el maestro lo vio y no le dijo nada.

\section{- Modelaje de la enseñanza}

No podemos taparnos los ojos nosotros mismos, hoy en día los avances de la tecnología brindan al adolescente gran cantidad de aplicaciones y juegos que lo distraen por muchas horas. El maestro debe de luchar con eso, no contra el alumno. Descubrir la forma en que su clase le resulte más interesante para que el alumno deje de lado su celular o su dispositivo. Quitárselos no es necesariamente la solución, porque se distraerán con cualquier otra cosa, o simplemente se abandonarán a la nada. El maestro debe entender y abrirse a las exigencias del alumno, buscar una enseñanza distinta, que haga al alumno moverse de su asiento para involucrase en la clase; usar nuevas herramientas tecnológicas, organizadores digitales, tutoriales hechos por los alumnos de un tema visto en clase, uso de apps en las tareas, videos, actuaciones, llenarlos de preguntas que reten su conocimiento y su búsqueda, en fin; ver con qué elementos cuenta el alumno y hacer uso de ellos. El diagnóstico también es una buena herramienta para descubrir esas herramientas. De esta forma la actitud del alumno cambiará, al darse cuenta que realmente al maestro le interesa que aprenda, no sólo que se entretenga con cualquier cosa. Cuando el alumno tiene cierto aprecio por el maestro, de alguna forma dentro de su proceso de identidad le copiará algunas características, 
pues lo ve como un modelo a seguir. Esta etapa es importante para el maestro, ya que puede ejercer una autoridad moral sobre el alumno para encaminarlo positivamente.

El modelaje no sólo se aplica en la didáctica, sino también en la formación. El alumno, decíamos anteriormente, buscará medir al maestro, es por eso que resulta esencial que el docente sea firme en sus decisiones, justo en las sanciones y coherente en su forma de calificar. Aquel alumno que en reiteradas ocasiones fue sancionado y recibe una calificación favorable en su conducta, sabrá que ese maestro no aplica las sanciones que dice, por lo que no verá ninguna consecuencia en sus actos y su actitud no cambiará, generando quizá, mismos conflictos con otros alumnos que se darán cuenta de eso provocando el cotidiano, ¿̇y por qué a tal compañero no le hizo nada? Es necesario entender que es el mismo alumno el que necesita esa firme autoridad, alguien que le ayude a marcar esos límites porque él mismo no es aún capaz de ponérselos.

Mismo elemento se aplica en las tareas y actividades en clase. Un alumno que no ve retroalimentado su trabajo por parte del maestro caerá en esta idea de hago como que trabajo, "de todas formas el maestro ni los revisa." De tal forma que, si la intención del alumno es que no sea castigado, buscará cumplir con las tareas, bien o mal hechas, o hasta copiadas; o si un alumno que entregó tarde o incompleta una tarea, recibe una misma ponderación que el alumno que entregó a tiempo y bien hecho, sabrá que no es necesario responsabilizarse, pues el maestro también se conforma con que sólo entreguen.

Algunos problemas que el docente encuentra dentro del aula es el control de los alumnos, específicamente cuando debe sancionar a uno que se ve cubierto por sus compañeros. En esta etapa, el adolescente buscará resguardarse y seguridad con sus compañeros de clase buscando su aceptación. Pero en realidad es un momento de inseguridad ante lo nuevo, los siguientes desafíos. Por lo que el docente debe encontrar los momentos de tranquilidad para dialogar con el alumno de forma individual, y no caer en juicios y buscar en todo momento castigos frente al grupo.

- Evaluación: ¿quién, ¿quiénes, ¿cómo, por qué y para qué?

Al inicio del ciclo escolar, es frecuente que el docente comente con su grupo la forma de evaluar el curso, establezca algunas ponderaciones fijas y dé la oportunidad que sus alumnos den otras, por 
ejemplo, a las tareas, la conducta, el portafolio, proyecto o a cualquier otro criterio que el docente quiera evaluar. La evaluación no debe hacerla solamente el maestro (heteroevaluación), es necesario que el alumno también forme parte de esa evaluación tanto al principio como en el proceso. Dejar que el maestro haga él mismo la evaluación no ayuda en nada: primeramente, porque se le quita al alumno su responsabilidad; y en segundo, no se están dando los espacios necesarios para identificar su avance ni su compromiso. Cuando un maestro involucra al alumno en las actividades, y en su evaluación (procesual, actitudinal, participativa) le hace ver al alumno que está al pendiente de él, que le interesa su desempeño, su desarrollo, y no solamente su calificación. De esta forma el maestro ayuda a que el alumno se dé cuenta que lo que hace o deja de hacer le afecta o ayuda a sí mismo, lo que se conoce como evaluación dialógica. Una pequeña autoevaluación de rendimiento puede ayudar a eso.

Es necesario tomar en cuenta las diferenciaciones que el adolescente tiene. Si se hace una evaluación estandarizada sin tomar en cuenta las problemáticas que puede llegar a tener cada alumno, caeríamos en lo que Perrenoud (2015) llamaba "función acreditativa" y de separación, donde el aula funcionaria como una estratificación de individuos; tú eres el bueno y listo; tú eres el malo y sin futuro; y al hacer esto, estamos suponiendo que todos los alumnos aprenden igual, tienen las mismas capacidades, aprenden al mismo ritmo y tienes los mismos intereses.

\section{Conclusiones}

No es la intención dar un recetario de clases, porque ciertamente eso es imposible. Una misma estrategia no funciona con todos los grupos, los alumnos no son los mismos, y van cambiando poco a poco, así como sus circunstancias etc. Sin embargo, sí es la de reflexionar sobre nuestra responsabilidad como docente, y el compromiso y valor que tenemos en cada uno de nuestros alumnos. Recordemos que Educar, no es solo transmitir e impartir temas: es conocer a nuestros alumnos, ayudarlos a conocerse, que descubran que tienen grandes talentos, es abrirles un abanico de posibilidades; comprender que la escuela no es un buzón para entregar tareas, sino un espacio ideal que les ayudará a crecer en conocimientos, habilidades, despertarles aquello que no sabían 
que eran buenos, darles metas, aspiraciones, un objetivo de vida, y hacerles ver que está en sus manos y sólo en sus manos el conseguirlo:

\section{Referencias}

Álava, M. (s/f) La educación es la llave del conocimiento y la antesala de la felicidad. BBVA. Aprendamos juntos: EL PAÍS. https://aprendemosjuntos.elpais.com/especial/no-basta-conquerer-a-los-hijos-tambien-hay-que-creer-en-ellos-maria-jesus-alava-reyes/

Bandura, A, y Walters, R. H. (1974) Desarrollo de la personalidad. Madrid: Alianza Universidad Barca, A., Peralbo, M., Porto, A.M., y Brenlla, J.C. (2008) “Contextos multiculturales, enfoques de aprendizaje y rendimiento académico en el alumnado de educación secundaria." Revista Iberoamericana de Educación. Número 46: Enero-Abril. Obtenida el 25 de octubre 2018 de: https://rieoei.org/historico/documentos/rie46a10.htm

Bolles, R, C. (1990) Teoría de la motivación. Investigación experimental y evaluación. México: Trillas Camps, V. (2008) Creer en la educación: la asignatura pendiente. Barcelona, España: Peninsula Eresta, M. J. (s/f) "Adolescentes de hoy aspiraciones y modelos." Liga española de la educación. Ministerio de sanidad, servicios sociales e igualdad. https://www.navarra.es/NR/rdonlyres/CA85EE8A-711C-4967-93BD362FBB0F2582/234022/Observatorio_Estudio_Aspiraciones_y_modelos_Parte1.pdf

Clauss, G. y Hiebsch, H. (1966) Psicología del niño escolar. México: Grijalbo

Gispert, C. (1989) Programa de formación de padres. Adolescencia. España: Ecisa

Guillén, R. (2005) "La adolescencia en el mundo actual". Revista de la Sociedad Boliviana de Pediatría. v.44 n.2. Recuperado el 2 de febrero de 2019 de http://www.scielo.org.bo/scielo.php?script=sci_arttext\&pid=S1024-06752005000200001

Lefrancois, G, R. (2000) Acerca de los niños. Una introducción al desarrollo del niño. México: Fondo de cultura económica.

Perrenoud, P. (2015) La evaluación de los alumnos. De la producción de la excelencia a la regulación de los aprendizajes. Entre dos lógicas. Buenos aires: Colihue. 
Siegel, D. (2018, noviembre, 19) Por qué la adolescencia es una etapa maravillosa de la vida. En: Aprendamos juntos. [Archivo de video] Recuperado de https://www.youtube.com/watch?v=6anw1uCBHuU 